\title{
Miningo
}

\section{Logistic evaluation of an underground mine using simulation}

\section{Avaliação da logística \\ de uma mina subterrânea utilizando simulação}

\begin{abstract}
This paper describes a logistic study about an underground gold mine, belonging to AngloGold Ashanti, where four different layout options could be applied to the tunnels, and also different transportation strategies. Each evaluated layout had its own configuration for shaft and truck fleets. The study was made individually for each year of the mine operation life, determining the necessary transportation capacity to achieve the planned production for that year. Due to the very restrictive traffic options in the tunnels, a framework was developed to represent the tunnels and traffic rules in a discrete-event simulation model. The results pointed the scenario with the lowest necessary transportation capacity to achieve the planned production.
\end{abstract}

Keywords: transportation capacity, simulation, ARENA.

\section{Resumo}

Esse artigo descreve o estudo de logística de uma mina subterrânea, pertencente à AngloGold Ashanti, em que quatro alternativas de transporte foram estudadas. Cada alternativa teve uma configuração específica para frota, silos e poço. O estudo foi feito individualmente para cada ano de operação da mina e determinou a capacidade de transporte necessária para se atingir a produção planejada naquele ano. Devido à especificidade do transporte e regras de tráfego do modelo, optou-se por utilizar o software de simulação ARENA. Os resultados apontaram o cenário com o menor número de frota e a maior capacidade de transporte para realizar o plano de produção.

Palavras-chave: capacidade de transporte, simulação, ARENA.

engenharia da Anglogold Ashanti

gmalkmim@anglogoldashanti.com.br

\section{Introduction}

AngloGold Ashanti is one of the largest gold producers around the world. Based at Johanesburgo, in South Africa, the company has 23 operations in 11 countries. There are more than 63 thousand employees globally.

In Brazil the main assets are located in the iron quadrangle in the state of Minas Gerais and also in the state of Goiás. The company operates three business units: Córrego do Sítio (in
Santa Bárbara, Minas Gerais); CuiabáLamego (in Sabará, Minas Gerais) and Serra Grande (in Crixás, Goiás). Besides this, the company has corporate offices located in the city of Nova Lima.

The largest production portion of the company comes from underground mine and open pits operations of South Africa $(40 \%)$ and Continental Africa (33\%). Brasil is responsible for $9 \%$ of its production followed by Australia. United
States represents $5 \%$ and Argentina 4\%.

In the business unit of CuiabáLamego, with the deepening of mining activities, the continuity of operations in a sustainable and profitable way is becoming a challenge. With depth, the continuity of operations are affected by an increase of average trucking distances, ventilation needs, infrastructure and ground conditions.

Inside this context of optimization 
and sustainability the transport system plays a key role, mainly in what refers to production rate maintenance in the long term. The fact of having a loading station at level 11 and with the current Business Plan going down to level 24, there will be a great impact on the average trucking distance and as a consequence, fleet increase, investment on infrastructure, ventilation and maintenance.

To search for the best alternative of the transport system that could reach required production levels with minor investment, Anglogold appealed to ARENA simulation software, since traffic in underground mines is a very dynamic process and very difficult to study with deterministic tools.

The concern about underground traffic in mines is not new. It is also subject to simulation studies since the early days of this technique being applied with computers. Hayashi and Robinson (1981) documented a simulation study regarding an underground railroad in a coal mine. They addressed traffic problems in detail, considering crossing lines, single lines and tunnel layouts. Their objective was also achieved for the best train configurations and dispatching strategies to sustain coal production with minimum resources.

The study conducted by Miwa and Takakuwa (2011) is also about a coal mine. They have evaluated an underground conveyor network, another option to retrieve minerals from the mine. In this case, the study was focused in the conveyor velocity, working under a predefined layout. Wu et al. (2013) have developed a simulation study regarding tunnel visualization of underground

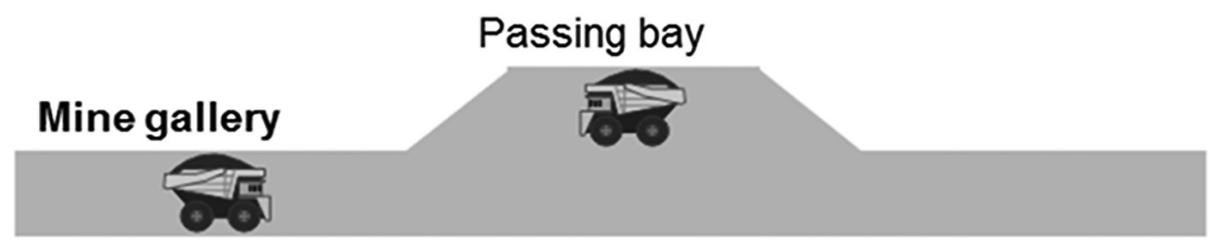

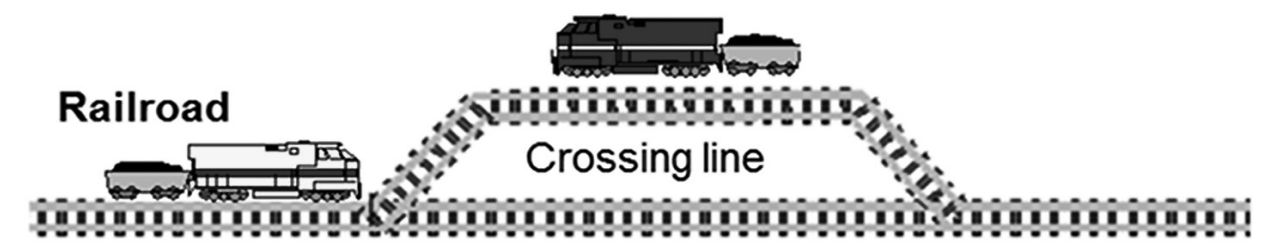

Since the traffic problems are similar, the solutions developed for railroad could also be applied to this case, with the necessary adjustments. Even the prioritization behavior is the same: loaded trucks should pass and empty trucks should wait. The chosen algorithm was the one proposed by
Fioroni et al. (2008), which addresses the line/tunnel restrictions, crossing rules and traffic behavior. The following sections describe how this study was conducted.

The purpose of this work is to demonstrate, through simulation, what is the best transport system for mines, but the transportation and traffic were not discussed.

When an underground mine uses trucks as the main transportation resource, the tunnel network may have traffic problems similar to a railroad network. Usually, the tunnels are large enough to allow only one truck to pass, sometimes two. Traffic situations like passing or crossing are not easy inside the mine. Almost every tunnel has structures called "mucking bays" or "passing bays", which are strategically located spaces that can accommodate one truck, sometimes more than one. When a truck is in a tunnel and another comes from the opposite direction, one of them parks into the passing bay and allows the other to pass. This is similar to a single railroad line with a crossing line, like presented at Figure 1.

\section{The underground mine problem overview}

To keep production rates with the safety levels required, in a profitable way and maximizing value to shareholders, the deepening of the mine must be studied in several aspects. From those we can highlight ventilation, refrigeration, infrastructure, rock mechanics and transport system.

At the current stage, the loading station is located at level 11 while the mining faces are located at level 15 (each panel is level to 66 meters in vertical extent). Considering that the current BUP goes down to level 24, an increase in average trucking distance and in the transport fleet would result in traffic congestion and as consequence this could impact the system production.

In the underground besides trucks there is also traffic from support vehicles, such as Jumbos, keep simbas, scalers and supervisory light vehicles that contribute to the impact of system productivity.

The software packages present in the market as Fleet Production and Cost Analysis from Caterpillar and Talpac make a deterministic approach on fleet evaluation. Talpac, besides the
Figure 1

Comparison between crossing

vehicles in a mine gallery and a railroad

Cuiabá mine. To develop this work some factors were used from which we can highlight the impact of traffic in cycle time.

This variable could not be reached by software available on the market as Fleet and Production Cost, and Talpac with their deterministic approach.

deterministic approach, has the Full simulation tool that makes a probabilistic approach to a fleet of trucks and loaders in a specific route of transport. The probabilistic approach from Talpac allows for the variation of key factors in fleet dimensioning as loader cycle time, trip time, dumping time, availability of fleet and payload of loader. For example if we run the simulation for 90 shifts, for each shift we would have a specific value, extracted from the probability charts.

This probabilistic approach is not sufficient to measure the impact on 
traffic conditions caused by the support fleet and crossing lines on transport ramps. As a consequence Anglogold Ashanti team recurred to Paragon, the representative office of ARENA in South America, to analyze and study the proposed scenarios.

The underground mine used to support this study is located in Brazil, at the Minas Gerais state. The available scenarios to be evaluated are a combina-

\section{Scenario 1: Original design}

This scenario is the original design for the mine, with four main access tunnels and a mix of trucks with capacity of tion of the following components:

- Tunnel layout

- Traffic directions

- Shaft loading position

- Intermediary silos: quantity and position

- Truck type and capacity

The trucks have mainly three tasks to accomplish: carry the gold ore to a shaft or hopper, carry waste to the shaft or hopper and carry waste to some

30 and 45 tons. It is considered the base scenario, used as a reference.

The schematic of the tunnel network mined out areas that need to be filled again. Trucks never go loaded to the surface. The mine has a limited number of loaders, which is the same for all scenarios. The loading points are changed according to the production schedule, going deeper at the mine.

After internal discussions and studies, the AngloGold team has selected four scenarios to be evaluated with simulation:

is presented at Figure 2. Each color square is a mining point at the level, and a brown square means a passing bay position.

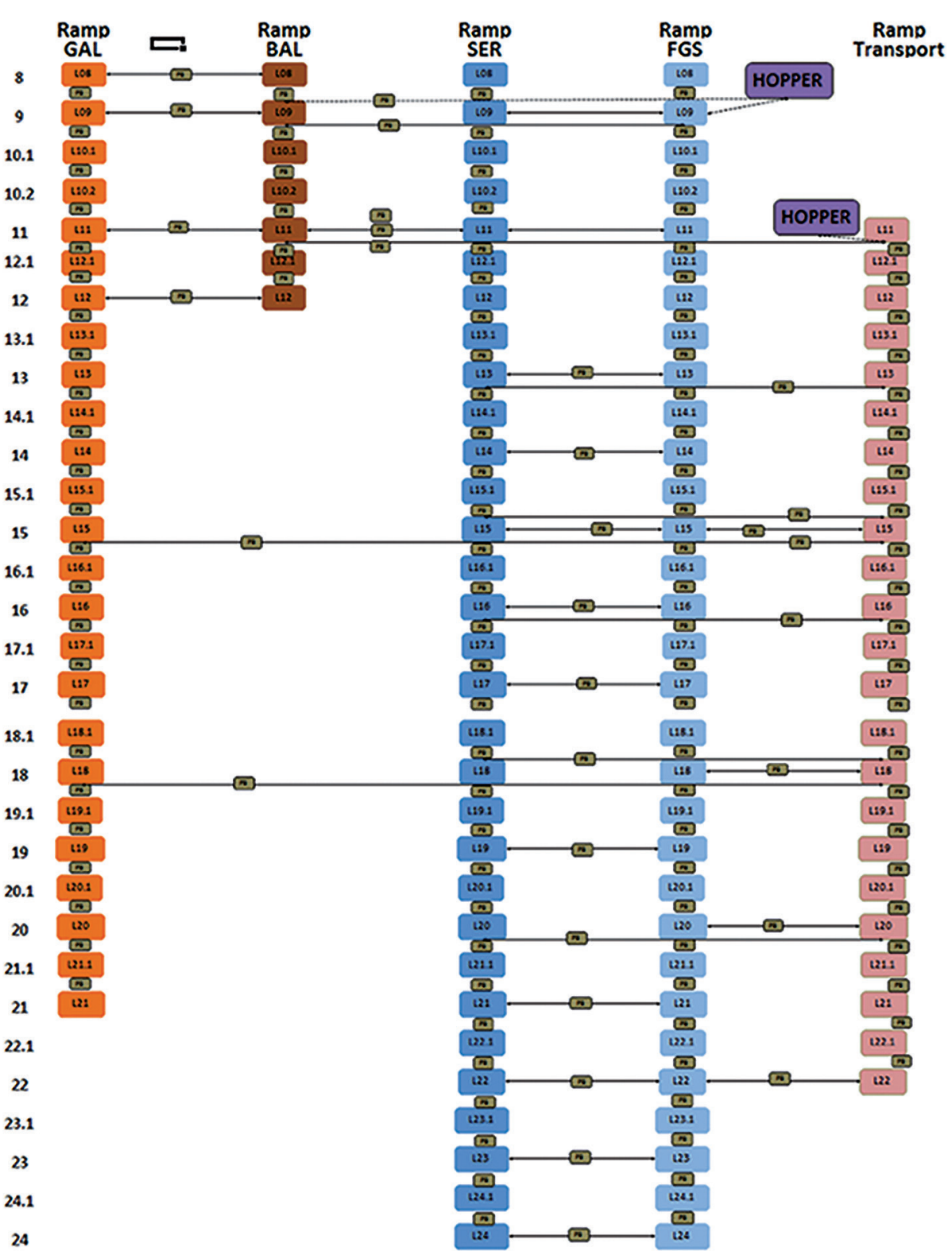

This scenario has a hopper at level 9 and the shaft is positioned at level

\section{Scenario 2: Deeper shaft position}

This scenario uses the same mix of trucks, but adding a new unloading posi-

11, providing two unloading points for the trucks.

tion at level 16, providing more options for the trucks, minimizing congestions. It is also nearest to the bottom of the mine. The tunnel layout is the same of scenario 1 . 


\section{Scenario 3: Intermediary silos}

This scenario uses the same tunnel network layout and unloading positions of scenario 1 , but intermediary silos were added at levels 15, 18, 20 and 22 . A fleet of 30 tons trucks is used to bring gold ore to the these silos, and after that, a fleet of 60 tons trucks is responsible for conveying it to the shaft position at level 11.

of scenario 1, with 30 and 45 tons of capacity. At figure 3 below, we can see layout changes:

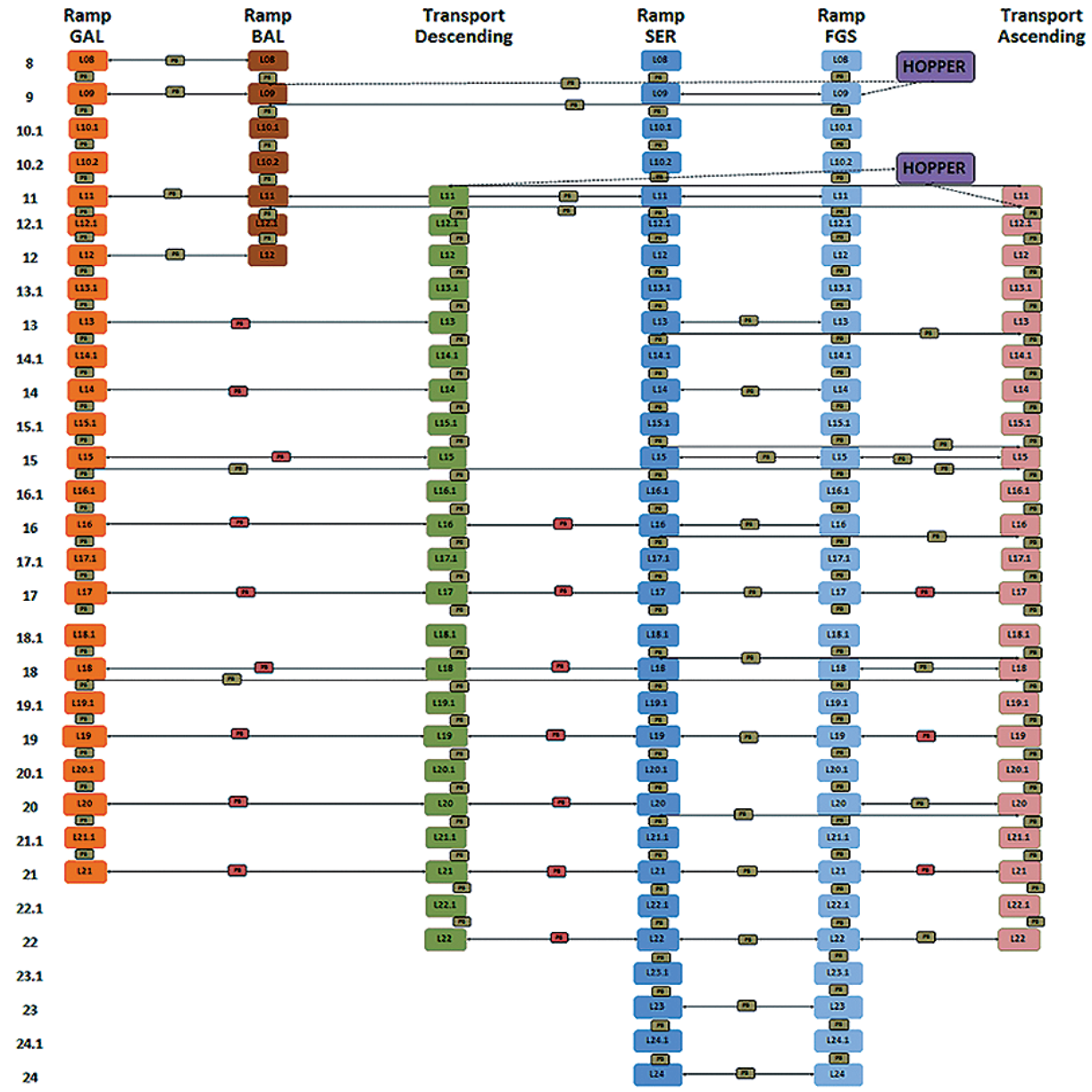

\section{Modeling the mine}

The simulation tool chosen to build the models was Arena, from Rockwell Automation. The approach to model the tunnel network was the one described by Fioroni et al. (2013), the signal oriented approach. It was chosen because the network had some particularities and another pre-existing tunnel as unidirectionally going up.

The truck fleet mix is also the same ing it as unidirectionally going down,

\section{The truck fleet mix is also the same}


do not really have this amount of light signals, but the truck advance is decided visually or by radio instructions, resulting in the same behavior.

The model has considered more than 2000 individual positions where the truck could load, unload, park or wait for other trucks to cross. The animation structure of the tunnel network is presented in Figure 4, where the signals can be seen along the lines.

The real network was too big to be represented, and a greater part of it was not important to the study. So, not all tunnels were represented; only the ones relevant to the process and with truck

\section{Model output}

A set of KPIs were implemented in the model to help the system validation and comparison between scenarios, spe-

Figure 5

Usage count for each route at the tunnel network

In addition, the model output has included the number of trips performed at each route inside the mine, in order

Figure 6

Usage count for each route at the tunnel network circulation. It was simplified, by removing irrelevant connections and aggregating common points.

Also, it was assumed that the truck should use only one path/route between positions. This helped to simplify the model and give some "room" in the results, since at the real mine the trucks could avoid tunnels with more traffic, taking better decisions than the model. But it was not considered relevant enough to affect the decision.

The routes were mounted by AngloGold personnel, since they have more knowledge about the mine, and where the trucks should pass on every trip between

cially travel and activity times and utilizations. Also, the scheduled production and simulated production were compared to positions. More than 10.000 routes were created, covering each possible origindestination pair in the model.

An individual model has been built for each scenario, due to structural differences between them. Evidently, the route's list had to be updated for each model.

All trucks and loaders are affected by downtimes and maintenance, and every movement of the trucks has a chance to be affected by disturbing vehicles, impacting its travel time. Although the priority in the mine is for the trucks, sometimes these may be affected by vehicles, such as personnel transportation, tunnel maintenance equipment, cars, etc.

confirm the goal achievement. A partial view of the output interface can be seen in Figure 5.

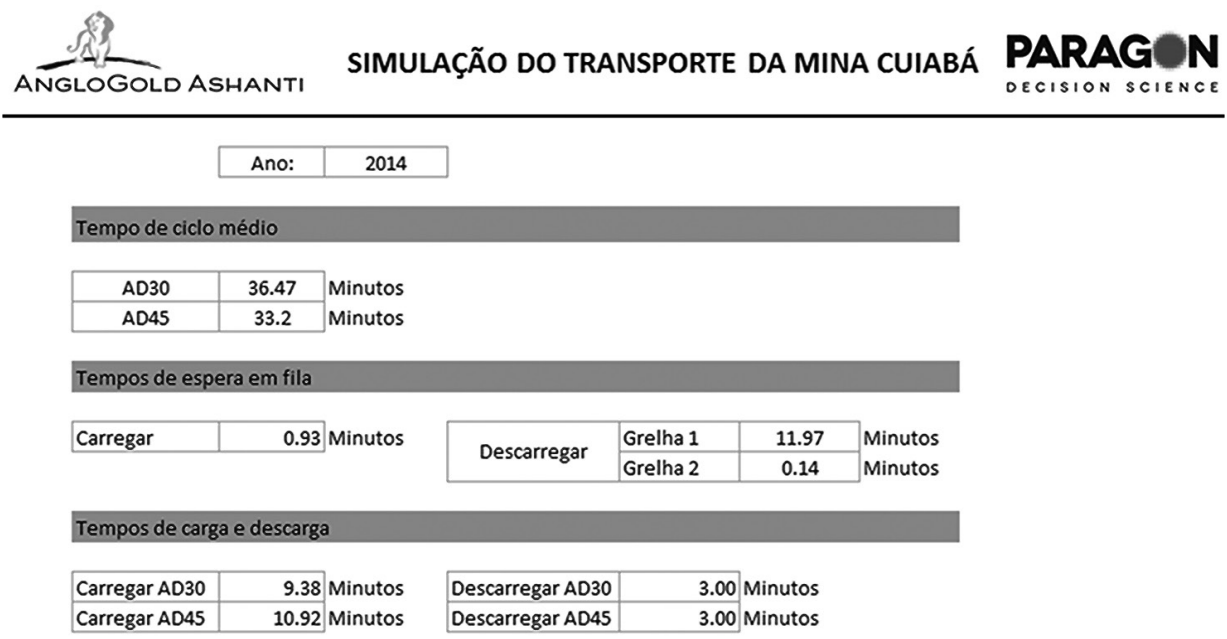

to provide the user useful information in Figure 6. about potential traffic problems and the most problematic routes, as can be seen

\begin{tabular}{|c|c|c|}
\hline Origem & Destino & Quantidade de escolhas(\#) \\
\hline st745 & st158 & 9340 \\
\hline st1934 & st950 & 9288 \\
\hline st315 & st164 & 3796 \\
\hline st733 & st158 & 3634 \\
\hline st7 & st1933 & 3394 \\
\hline st1934 & st938 & 2872 \\
\hline st25 & st1935 & 2553 \\
\hline st1 & st1933 & 2487 \\
\hline st739 & st158 & 2185 \\
\hline st1934 & st176 & 2164 \\
\hline st1936 & st552 & 2116 \\
\hline st751 & st164 & 1901 \\
\hline st31 & st1935 & 1809 \\
\hline st1934 & st956 & 1756 \\
\hline st1936 & st630 & 1740 \\
\hline st395 & st164 & 1588 \\
\hline
\end{tabular}




\section{Model validation}

The model was validated by comparing its results with deterministic calculations made for the base scenario (scenario 1).

\section{Scenarios results}

Several experiments were made with each scenario, to determine the optimal truck fleet at each year of operation. The objective was to find the lowest fleet, able to achieve $95 \%$ or more of the

where: F1: Trucks of fleet 1 ; C1: Truck capacity at fleet 1 ;

The TTC was calculated for all

TTC Total Transportation Capacity (tons)

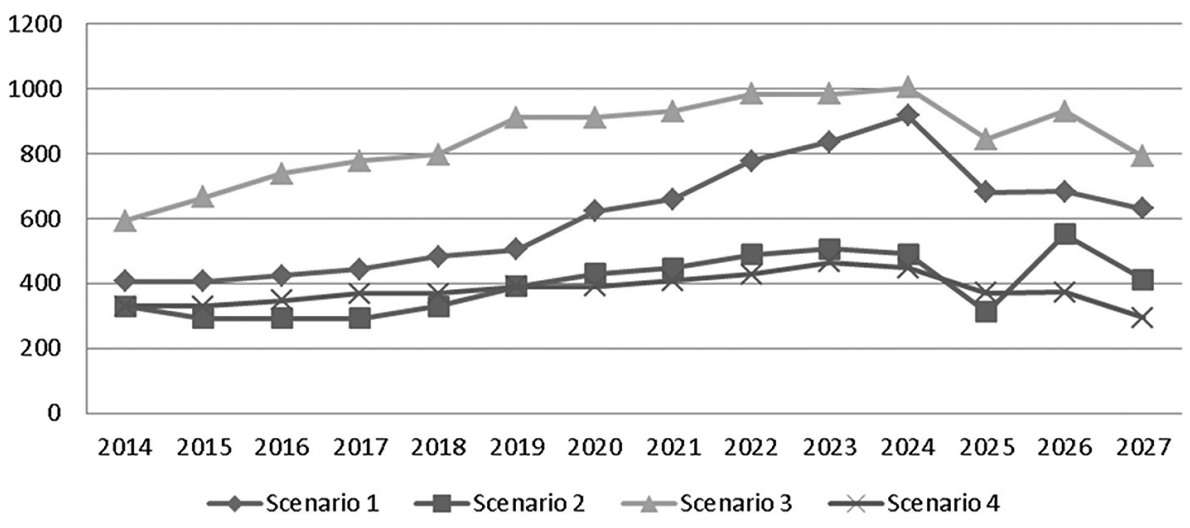

Evaluating this KPI, scenario 2 and 4 performed noticeably better than 1 and 3. The production has a peak at 2024 and a reduction at 2025 . The transportation capacity required for this year in all scenarios can be noted. The following year,
2025, isn't so demanding, requiring less trucks. These sudden changes in the number of trucks from one year to another are inconvenient and should be avoided.

The other utilized methodology was the transport momentum expressed in
Also, all results were analyzed by the mining experts to check for coherency.

The model behavior was evaluated

scheduled production.

In order to compare the scenarios, a new KPI was proposed, since the truck type was not the same for all scenarios and the direct comparison would not

$$
\text { TTC }=\left(F_{1} * C_{1}\right)+\left(F_{2} * C_{2}\right)
$$

F2: Trucks of fleet 2,

C2: Truck capacity at fleet 2 .

scenarios and used to generate the chart

presented at Figure 7 below. with sensitivity experiments.

After that, AngloGold team has approved the model to proceed with scenario experiments.

be possible. This KPI was named "Total Transportation Capacity" (TTC) and is a sum of capacities of all trucks of the two different fleets measured in tons, as presented below:
Figure 7

Comparison between scenarios

tkm per truck. This and the TCC analysis, allowed the creation of a comparison between scenarios in the same base.

Depicted below there are the charts with quantities of trucks per each scenario:

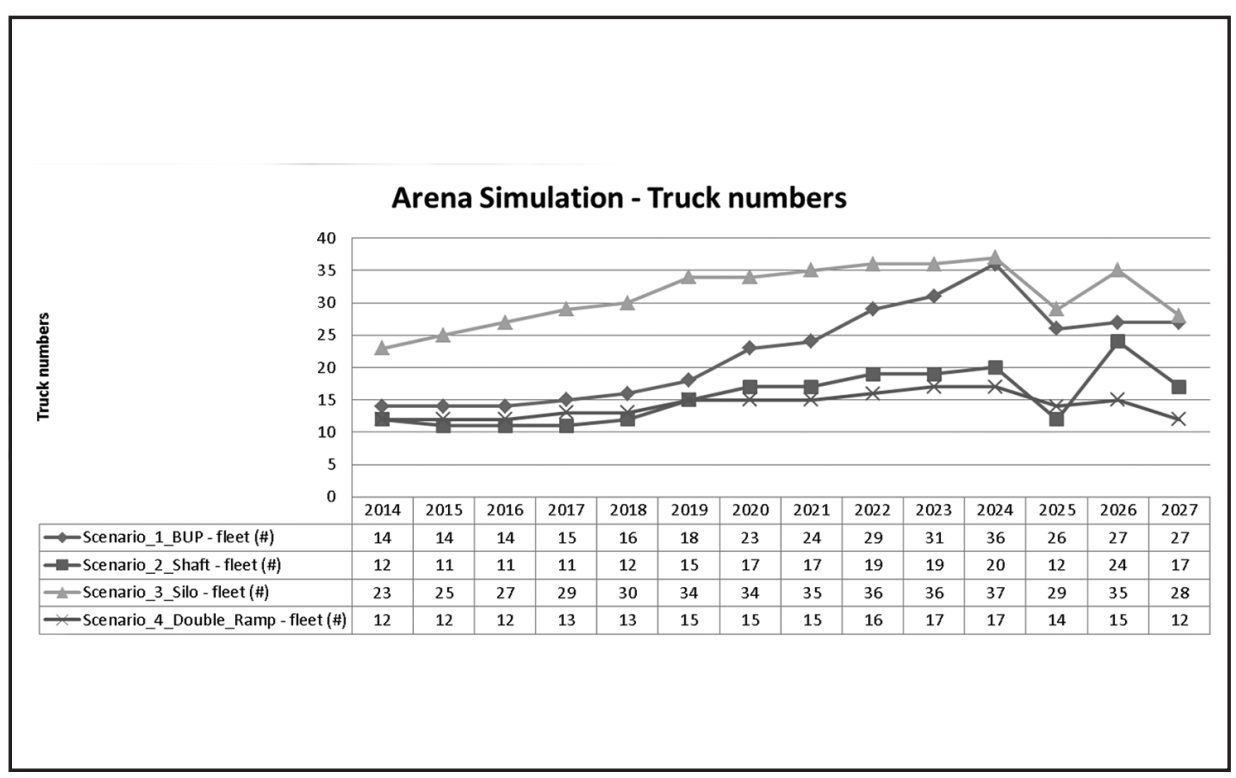

Figure 8

Trucks numbers for each scenario

In sequence we have the average cycle time for each scenario: 
Figure 9 Average cycle time for each scenario And then in the end, we have the av-

\section{Figure 10}

Average trucking distance for each scenario

As the production profile considered was the same for all scenarios the tkm

Figure 11 tkm for each scenario

After dividing the tkm by the truck numbers for each scenario, we reach a

Figure 12 tkm per trucks per each scenario

On one hand, this kind of analysis has shown that scenario 4 is more productive when compared to the others. On

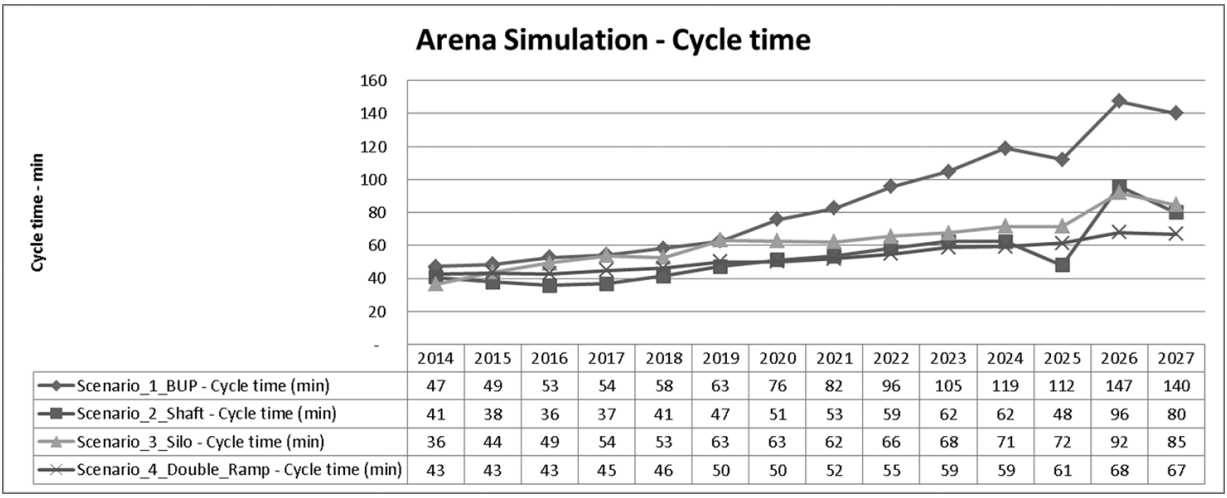

erage trucking distances for each scenario:

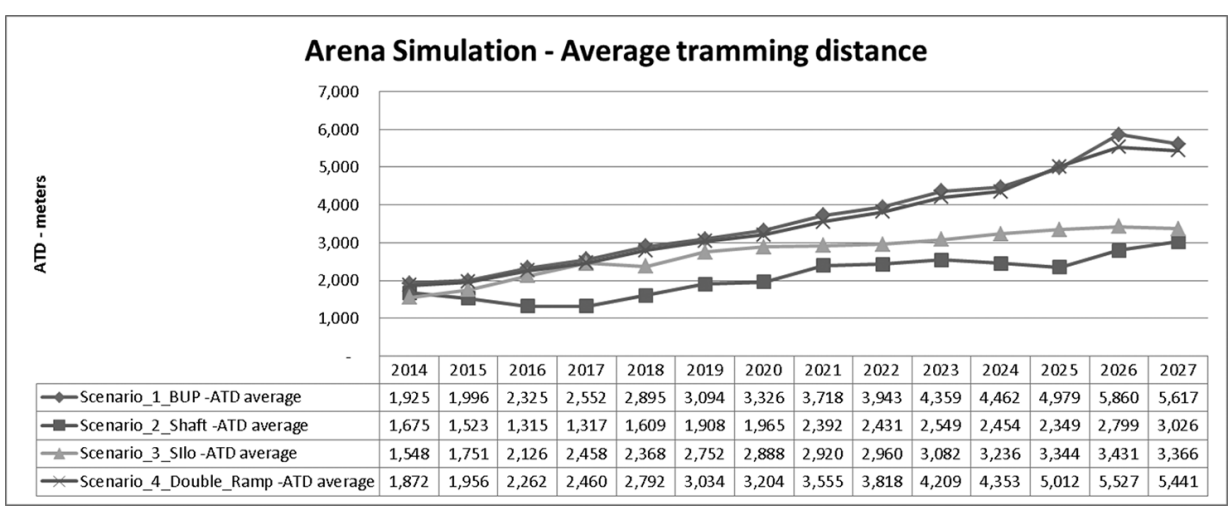

charts vary proportionally to trucking

distances as in Figure 11 below:

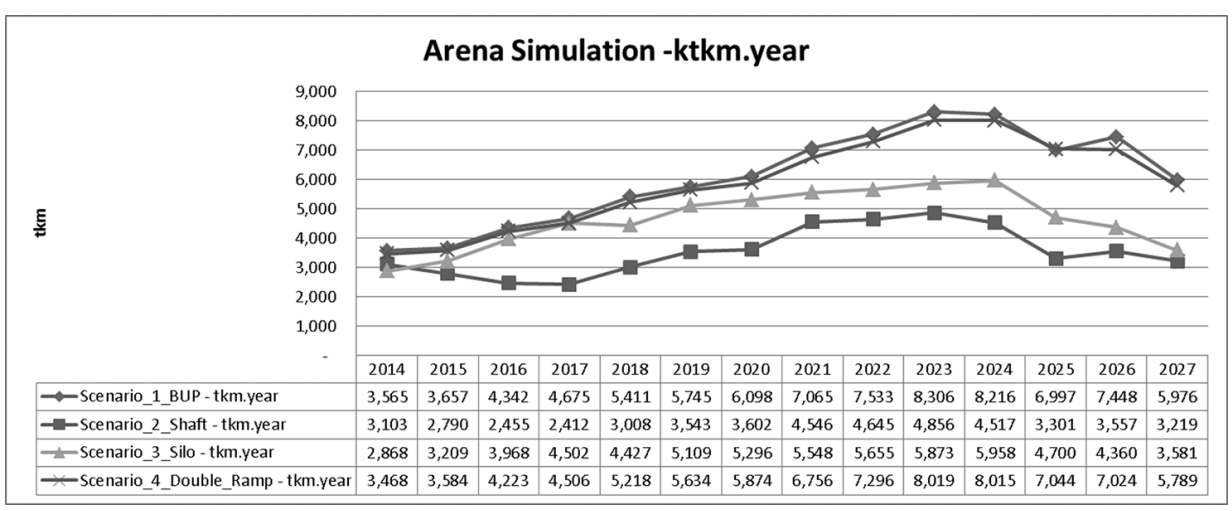

KPI, that similarly to TCC, allows us to on the same basis. make a comparison between the scenarios

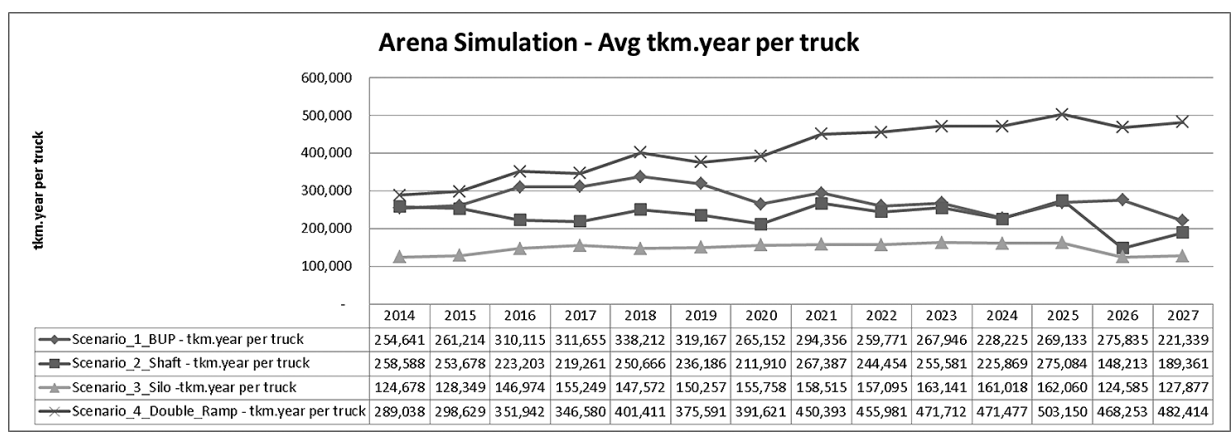

the other hand, scenario 3, was the least efficient and required a bigger number of trucks to transport the mass of the pro- duction plan. In future analyses, those values could be improved if we adopt trucks without ejectors and increase their 
operational capacity.

Regarding the KPI of $\mathrm{tkm}$ for each truck in scenarios 1 and 2, we can observe that they are very similar despite the differences in the average trucking distances. This occurs because with

\section{Conclusion}

By the results obtained and model behavior, it is possible to conclude that the railroad algorithms and approach adopted were appropriate to represent underground mine truck traffic behavior. All scenarios could be modeled and considered validated by the mine specialists. This is a relevant achievement because to model restrictive movement is always a challenge. Not the restriction itself, but the entire decision process that has to be present to allow the truck or train to move in this structure.

One weak point in this study is the absence of a dispatch system in the model that will probably exist in the real system. Besides, as it would not be perfect or optimal, this could allow the trucks to choose a better path or decide for a different destination depending

\section{References}

shaft deepening, there is a decrease in truck numbers and also smaller average trucking distance. As a result the tkm per truck is very similar to those numbers of scenario 1. Those results can lead us to conclude that shaft deepening is not as impacting as we expected.

To choose the best scenario, Anglogold Ashanti will make the economic analysis of each one and will use also other criteria as implementation time and operational complexity. on the present situation at the mine. In this case, however, as mentioned before, it was not considered relevant to this study. In fact, the fleet determined with the model will be a little bit higher than the one necessary for the real system. On the other hand, the comparison between scenarios is not affected at all. All of them share the same weaknesses, which become irrelevant when comparing scenario data. They are all affected in the same way and at the same level, meaning the comparison is very reliable.

This study was focused on productivity and fleet size to decide the best scenario.. There are other factors involved in this choice, such as the investment necessary to implement the infrastructure, the implementation schedule, and the complexity and risks that are going to be analyzed in a next step and were not objects of this study.

The KPI's as TTC and tkm pointed out scenario 4 as the best option in both scenarios.

This study showed us the capacity of simulation software to model and represent traffic issues found in underground mines. The fleet dimensioning software available on the market does not allow a more deep and detailed analysis on the traffic and transport system as the analysis did by Paragon using ARENA.

The software Fleet Production and Cost and Talpac, works with a fleet dimensioning for a single face or production area but do not offer tools that consider the traffic influence segment by segment.

CATERPILLAR Dealer Channel Systems. Fleet production and Cost analysis. U.S.A.: Caterpilar, 2010. (Version 2).

FIORONI, M. M., QUEVEDO, J. G., SANTANA, I. R., FRANZESE, L. A. G., CUERVO, D., SANCHEZ, P., NARDUCCI, F. Signal-oriented railroad simulation. In: PASUPATHY, R., KIM , S. H., TOLK, A., HILL, R., KUHL, M.E. In: PROCEEDINGS OF THE 2013 WINTER SIMULATION CONFERENCE. Piscataway, New Jersey: Institute of Electrical and Electronics Engineers, Inc. P.35333543, 2013.

Fioroni, M. M. 2008. Simulação em ciclo fechado de malhas ferroviárias e suas aplicações no Brasil. São Paulo: Escola Politécnica, Universidade de São Paulo, 2008. (Ph. D. Thesis). http://www.teses.usp.br/teses/disponiveis/3/3135/tde-03062008 180002/pt-br.php [Accessed February 27, 2014].

HAYASHI, F., ROBINSON, D. 1981. Computer Simulation of Mine Rail Haulage System. In: Oren, T.I, DELFOSSE, C.M, SHUB, C.M. (Eds). In: PROCEEDINGS OF THE 1981 WINTER SIMULATION CONFERENCE. Piscataway, New Jersey: Institute of Electrical and Electronics Engineers, Inc. P.121-127, 1981.

MIWA, K., TAKAKUWA, S. Operations modeling and analysis of an underground coal mine. In: JAIN, S., CREASEY, R. R., HIMMELSPACH, Y., WHITE, K. P., FU, M. (Eds.) In: PROCEEDINGS OF THE 2011 WINTER SIMULATING CONFERENCE, edited by S. Jain, R.R.. Piscataway, New Jersey: Institute of Electrical and Electronics Engineers, Inc. P. 1685-1695, 2011.

Runge Limited Talpac, Release 10.1.4. Copyright (C) 2005 - 2010, Brisbane Australia. WU, S., LU, M., MAO, S., SHEN, X.. As-built modeling and visual simulations of tunnels using real-time TBM positioning data. In: PASUPATHY, R., KIM, S.H., TOLK, A., HILL, R., KUHL, M.E. (Eds.). In: PROCEEDINGS OF THE 2013 WINTER SIMULATION CONFERENCE. Piscataway, New Jersey: Institute of Electrical and Electronics Engineers, Inc. p. 3066-3073, 2013. 